\title{
Customer Satisfaction: Does Player Perception of Clay Court Quality Affect Court Maintenance Requirements? Evidence from Daily Maintenance and Player Feedback
}

\author{
David Spohn ${ }^{1} \&$ Tim Plossl ${ }^{2}$ \\ ${ }^{1}$ Researcher, USA \\ ${ }^{2}$ Tennis Director, Brandon Sports and Aquatic Center, USA \\ Correspondence: David Spohn, Researcher, USA
}

Received: August 2, 2018

doi:10.11114/bms.v4i3.3509
Accepted: August 29, $2018 \quad$ Online Published: August 30, 2018

URL: https://doi.org/10.11114/bms.v4i3.3509

\begin{abstract}
This paper investigates participants' perception of the quality of clay tennis courts (i.e. satisfaction) and its effect on costly court maintenance requirements. Using unique participant data collected at a tennis facility located in Brandon, Florida from November 1, 2017 to November 30, 2017, the use of structural equation modeling techniques show that participants' perceptions are influenced by on-court amenities. Conditional regression analysis is used to confirm the findings and reflects that participant perception of the quality of clay courts is influenced by availability of shade (for breaks) and clarity of lines. After adjusting for participant skill level, the analysis finds that more skilled players are less likely to be influenced on the quality of clay courts by on-court amenities. The analyses confirm that by focusing on customer satisfaction, maintenance cost reduction can be realized.
\end{abstract}

Keywords: customer satisfaction, sports operation, facility management, consumer behavior

\section{Introduction}

Does player perception dictate clay court maintenance requirements? There is very little literature on player perception (i.e. satisfaction) combining clay court maintenance requirements. While most sports facilities that offer clay courts (tennis) have maintenance requirements, very little is offered on player feedback and either the reduction of maintenance cost or the increase of maintenance cost based on player perception. This paper focuses on the role of player perception of quality and its direct impact on clay court maintenance (i.e. maintenance cost requirements).

With an estimated 83 million participants globally (Sports Marketing Surveys, 2005), tennis is widely considered a popular international sport for recreational players, competitive players, and professional players. Like other sports, its popularity fluctuates from year to year. The United States for instance is currently experiencing a declining number of participants (TIA, 2004; Martin, 2015). The Tennis Industry Association (TIA) contributes the declining interest in tennis to competition between other leisure activities.

Previous studies examine tennis from the perspective of constructs measuring satisfaction by focusing on loyalty (Kang, 2002), involvement (McGehee, Yoon, \& Cardenas, 2003), intention (Haggar, Chatzisarantis, \& Biddle, 2002), and motivations (Milne \& McDonald, 1999). Due to competition between other activities and the costs associated with clay court maintenance, sports facilities are increasingly trying to find ways to keep players involved in tennis while reducing costs. Thus, the premise focuses on measuring player perception of the quality of clay courts in attempt to reduce maintenance costs as well as keep and retain members (while encouraging others to participate) based on outside court factors, on-court amenities, personal (player) equipment, and court preparation (maintenance). This paper fills a void by employing data on player perception of the quality of clay and court maintenance cost reduction and finds that focusing on player perception (satisfaction) can reduce court maintenance costs.

\section{Literature Review}

While customer satisfaction in tennis is underdeveloped, perceived value and satisfaction in the literature are not. Perceived value is considered a function of fairness (Oliver, 1997), where customers receive what they expect. Satisfaction, often thought of as equity theory is a measure of a customer's perceived value compared to a company's 
output value (Oliver \& DeSarbo, 1988). This unique relationship compliments the idea of perceived sacrifices and perceived quality (Bolton \& Lemon, 1999) where customers who favorably view quality are more likely to stay engaged with the organization's offering (Minocha, Dawson, Blandford, \& Millard, 2005). While quality, price, and company/brand image are factors associated with value, customers are more inclined to evaluate quality (Fredericks \& Salter, 1998). Prevous studies validate the positive relationship between perceived value and satisfaction (Oliver, 1997; Oliver \& Swan, 1989).

We know from previous studies that a positive relationship between perceived value and satisfaction lead to customer loyalty (Zeithaml, Berry, \& Parasurman, 1996). Cronin and Taylor (1992) find that quality precedes satisfaction; however, quality is less important than satisfaction, and satisfaction has a significant effect on loyalty. Dabholkar, Shepherd, and Thorpe (2000) use structural equation modeling and find that customer satisfaction mediates quality on loyalty. This unique relationship between quality, satisfaction and loyalty indicates that high perceived quality and high satisfaction lead to a high level of loyalty (Taylor, 1997). Conversely, customer complaints lead to dissatisfaction (Singh, 1988). Thus, this study looks to utilize the relationship between the perceived quality of the clay courts and customer satisfaction to increase loyalty, while reducing tennis-specific maintenance costs by focusing on what consumers (tennis players) value.

\section{Background and Hypotheses Development}

While many sports facilities would like to employ a robust court maintenance staff and spend tens of thousands of dollars monthly offering clay courts that could rival premium facilities such as that of Roland Garros (host of the French Open), it simply is not cost efficient. Members and guests are not willing to pay membership or playing fees (guest fees) associated with playing on such premium surfaces on a regular basis. Additionally, it is not generally prudent for the average sports facility or country club to invest large sums of money to build, retain or maintain such clay courts due to low profit margins associated. Declining interest and participation in tennis within the United States (TIA, 2004; Martin, 2015) does not make it economically feasible to spend an exorbitant amount of money to offer such premium courts.

Thus, this study seeks to provide the most economically sound solution for clay court maintenance by gaining valuable on-court participant information on how participants perceive the quality of clay courts (satisfaction). This study is modeled after perceived service quality which emphasizes the difference between expectation and perception (Parasuraman, Zeithaml, \& Berry, 1985) and measures the distinction between the two, and revolves around expectations and perceptions influencing satisfaction (Tsiotsou, 2006). We measure customer satisfaction by using the expectancy disconfirmation theory (Erevelles \& Leavitt, 1992) where performance level is measured as compared to expectation.

While previous studies classify attributes into dimensions to measure the difference between expectations and perception (Tseng \& Hung, 2013), there is a significant lack of literature that measures participants' perception of the quality of clay courts. We use the American Customer Service Index (ASCI) model to measure the antecedents of satisfaction by focusing on perceived quality, value and expectations. Due to the unique nature of this study, the differing determinants are isolated. We only analyze the perception of the quality of clay to measure satisfaction. To mitigate this inherent short-coming, the development of a survey with a sample of 8 members of a neighboring tennis facility with the input of 3 United States Professional Tennis Association (USPTA) professionals is used to measure player perception of quality of the clay courts.

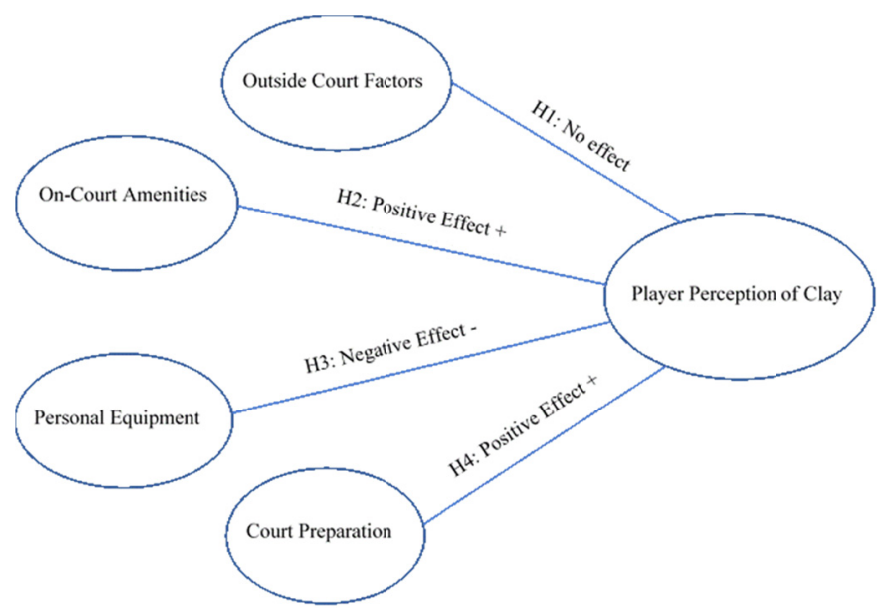

Figure 1. Conceptual Model and Hypotheses 
Extensive maintenance in-and-around the tennis courts reflects that labor and cost do not match what participants' satisfaction represent in the pilot study. Thus, the logical conclusion based on previous literature is that if participants' expectations match or exceed their perception of the quality of clay courts, participants will be more likely to continue their memberships and participation at the tennis facility. Thus, the study hypothesizes the following:

Hypothesis 1. Outside Court Factors have no effect on Player Perception of Quality of Clay Courts.

Through expectations and participant norm (Noble, Haytko, \& Phillips, 2009), bias enters or influences certain expectations. Participants' negative feelings or impressions are more likely to influence perception, as are positive feelings (Kotler \& Keller, 2006).

Hypothesis 2. On-Court Amenities have a positive effect on Player Perception of Quality of Clay Courts.

Using the same logic as hypothesis 2, participant norm and referents influence perceptions (Kotler \& Keller, 2006). While control for each participant's personal equipment is not feasible, there should be an interaction between personal equipment used by the participants and thus conclude:

Hypothesis 3. Personal Equipment has a negative effect on Player Perception of Quality of Clay Courts.

Direct observation and immediate feedback reflect that court preparation does influence the quality of clay courts, while the aim of this study is to show a direct relationship between court preparation and the perception of the quality of clay courts. By eliminating selection bias, the study should reflect:

Hypothesis 4. Court Preparation has a positive effect on Player Perception of Quality of Clay Courts.

Based on satisfaction, the analysis aims to look at factors both on the clay court and off the clay court to determine if there is a negative (positive) relationship that impacts player perception of the quality of clay courts. If the hypothesized relationships exist, the goal is to determine what court maintenance requirements best enhance player perception of quality of clay courts, thus reducing maintenance costs by focusing on what members and participants view as most important.

This paper enriches the understanding of player perception of the quality of clay courts by examining relationships that influence participant perceptions of satisfaction to reduce maintenance costs.

\section{Data and Methodology}

Data is gathered from members and participants from a sports facility located in Brandon, Florida. The facility offers 4 hardcourts (court numbers 1-4) and 6 clay courts (court numbers 5-10). The data set is solely focused on the 6 clay courts and collects information from each participant as they depart the clay court including ${ }^{1}$ : Date, Court Number, USTA Level, Reason for Play, Sky, Wind, Temperature, Water, Shade, Lines, Net, Clay, Restroom Appearance, Racquet, Strings, Grip, and Tennis Balls. The daily conditions are annotated for each day of the survey and comprise: Temperature (Actual), Weather Conditions, Wind (Actual), Cloud Cover, Preparation (Courts), and Water Time (Minutes). The data is collected from November 1, 2017 through November 30, 2017 (i.e. 120 participant observations). Table 1 provides descriptive statistics on these data, including the sample mean, standard deviation, minimum and maximum values of each respective variable.

Table 1. Descriptive Statistics

\begin{tabular}{|c|c|c|c|c|}
\hline & Mean & Std & Min & Max \\
\hline Date & N/A & N/A & $11 / 1 / 2017$ & $11 / 30 / 2017$ \\
\hline Court \# & $\mathrm{N} / \mathrm{A}$ & N/A & & 10 \\
\hline USTA Level & 3.5 & .3929 & 2.5 & 4.5 \\
\hline Sky & 1.73 & 1.137 & 1 & 5 \\
\hline Wind & 1.61 & 1.137 & 1 & 3 \\
\hline Temperature & 3.93 & .847 & 1 & 5 \\
\hline Water & 5.83 & .923 & 3 & 7 \\
\hline Shade & 5.03 & 1.606 & 1 & 7 \\
\hline Lines & 4.85 & 1.281 & 2 & 7 \\
\hline $\mathrm{Net}$ & 3.56 & 2.016 & 1 & 7 \\
\hline Clay & 5.63 & 1.322 & 1 & 7 \\
\hline Restroom & 3.91 & 1.322 & 1 & 7 \\
\hline Racquet & 3.39 & 1.292 & 1 & 5 \\
\hline Strings & 2.48 & 1.145 & 1 & 5 \\
\hline Grip & 2.11 & 1.098 & 1 & 5 \\
\hline Tennis Balls & 1.33 & .823 & 1 & 5 \\
\hline
\end{tabular}

\footnotetext{
${ }^{1}$ These variables are chosen based on feedback from the pilot study at a neighboring facility. The pilot study group's consensus on factors affecting the quality of clay courts is based on conditions that were deemed appropriate by the USPTA (tennis) professionals.
} 
This table presents summary statistics on data collected from the participants from November 1, 2017 through November 30, 2017. The overall sample includes 120 observations. Date, Court Number, and USTA Level are self-reported. Sky (player perception), Wind (player perception), Temperature (player perception) are reported based on a five-point Likert scale where a value of 1 = "favorable.". Water (on court), Shade (on court), Lines (visibility), Net (condition), Clay (perception), and Restroom (appearance) are reported based on a seven-point Likert scale where a value of 1 = "unfavorable." Racquet (age), Strings (age), Grip (age), and Tennis balls (age) are reported on a five-point Likert scale where a value of $1=$ "new."

The sample for this study comprises participants from members of the facility, guests of the facility, high level junior players, and participants from area (local) facilities playing in leagues. The survey is developed using feedback and recommendations from a sample of members of a neighboring tennis facility (8) with additional input from 3 United States Professional Tennis Association (USPTA) professionals to measure player perception of the quality of clay courts. The survey is distributed consisting of 17 questions comprising of the date, level of play (experience), reason for play (league/competitive or recreational), weather conditions, court amenities, and personal equipment. Of the total of 328 surveys that are distributed, 218 surveys are returned for a $66 \%$ response rate. Of the survey responses, 98 are incomplete or missing required data. This left an unstable sample of 120 surveys for an effective response rate of $37 \%$.

Table 1 reflects the sample means of the variables as well as the standard deviations. The maximum and minimum values do not suggest significant data abnormalities and appear to be within general expectations of the sample.

Given the unique nature of tennis and this study, each variable is not overtly intuitive. Thus, the definition of each of the variables is included to provide clarity. Each survey respondent is given a short instructional brief on filling out the survey, answer any questions regarding the survey, and a simple definition of each of the defined Likert scale responses.

Outside Court Factors comprise of variables generally associated with the weather: sky, wind conditions, and temperature. The scale uses a five-point Likert scale with responses ranging from (1) "favorable" to (5) "unfavorable", with the intent of measuring each participant's perception of the variable.

Sky: defined as the amount of sun experienced while playing

Wind Conditions: how windy the conditions appeared to have been while playing

Temperature: how cool/hot the temperatures on court felt to the respondents

On-Court Amenities comprise of variables associated with available amenities stationed as a part of the court or in-and-around each court: water, shade, lines, net, clay court, and restrooms. The scale uses a seven-point Likert scale with responses ranging from (1) "unfavorable" to (7) "favorable", with the intent of measuring each participant's perception of the variable.

Water: availability of drinking water on-court, and whether it was cold (hot)

Shade: availability of shade (for breaks between games)

Lines: visibility of lines and how worn they appear to the participants

Net: appearance and apparent wear (age due to holes)

Clay Court: plushness of the court (i.e. too dry vs. smooth/wet)

Restroom: appearance and adequacy of the facilities

Personal Equipment uses variables associated with each individual player: racquet, strings, grip and balls (used for play during that session). The scale uses a five-point Likert scale with responses ranging from (1) "new" to (5) "worn."

Racquet: age of racquet (newness/recently purchased)

Strings: newness of strings in racquet

Grip: newness/age of replacement grip on racquet used during session

Balls: age of tennis balls used during session

Court Preparation uses control variables collected by the staff which include: wind (actual), cloud cover (percentage), preparation (court), and water time. These variables are collected daily and annotated at the start of each participant's playing session.

Wind (actual): the wind in miles per hour based on our location (from weather.com)

Cloud Cover: the percentage of cloud cover based on our location (from weather.com) 
Preparation: the steps taken to get the courts ready for play in the morning prior to the participants beginning play. Different preparation set-ups include all or a combination of: rolling the court, sweeping the court (brush), lining the court (brush), and hand-scrubbing the lines (clarity)

Water Time: the amount (in minutes) of the above ground watering system placed on the courts during the previous night.

\section{Empirical Results}

\subsection{Analytical Procedures}

Structural equation modeling is used to examine the relationships between the models and variables (Dabholkar, Shepherd, \& Thorpe, 2000). Prior to examination of the relationship between the variables and the perception of the quality of clay, the study first evaluates the factor structure of the scales using confirmatory factor analysis. The hypothesized model is evaluated, and then compares it to several other measurement models to determine which model best fits the data. Computation of the means standard deviations, composite reliabilities, and intercorrelations among the variables are calculated. The hypothesized relationships between the perception of quality of clay courts, outside court factors, on-court factors, and personal equipment as well as the mediating influence of maintenance preparation of the clay courts and watering time (of the previous night) are evaluated using structural equation modeling procedures.

\subsection{Evaluation of Measurement Model}

A series of tests of the confirmatory factor models is used to evaluate the factor structure of the variables. The first test of the factor solution (Model 1) includes all variables: Court Number (court played on), USTA Level (self-reported skill level), Sky (player perception), Wind (player perception), Temperature (player perception), Water (on court), Shade (on court), Lines (visibility), Net (condition), Racquet (age), Strings (age), Grip (age), Tennis balls (age), Wind (actual), Cloud Cover (percentage), Preparation (of court), and Water Time (of the previous night). Two additional 4-factor models are evaluated. Model 2 includes: Sky (player perception), Wind (player perception), Temperature (player perception), Water (on court), Shade (on court), Lines (visibility), Net (condition), Racquet (age), Strings (age), Grip (age), Preparation (of court), and Water Time (of the previous night), eliminating (from the previous model), Court Number, USTA Level, and combining Wind (actual) with Wind (player perception) as well as Sky (player perception) and Cloud Cover (percentage). The last model (Model 3) includes: Sky (player perception), Wind (player perception), Temperature (player perception), Water (on court), Shade (on court), Lines (visibility), Net (condition), Racquet (age), Strings (age), Preparation (of court), and Water Time (of the previous night), further eliminating Grip (age). Model 3 combines Wind (actual) and Wind (player perception), as well as Sky (player perception) and Cloud Cover (percentage). The fit estimates are shown in Table 2.

Table 2. Confirmatory Factor Analysis Measurement Model Fit

\begin{tabular}{lccccc}
\hline & $\chi^{2}$ & $(\mathrm{df})$ & CFI & SRMR & RMSEA \\
\cline { 2 - 6 } MODEL & & & & & \\
Model 1 & $719.591 * * *$ & $(120)$ & .38 & .292 & .174 \\
Model 2 & $454.667 * * *$ & $(116)$ & .89 & .291 & .172 \\
Model 3 & $189.471 * * *$ & $(111)$ & .91 & .261 & .168 \\
\hline
\end{tabular}

This table presents confirmatory factor analysis measurement model fit for the three models examined in this study. Chi-square $\left(\chi^{2}\right)$ as well as the degrees of freedom (df) are reported in the first and second columns, followed by the Comparative Fit Index (CFI), the Standardized Root Mean Square Residual (SRMR), and the Root Mean Square Error of Approximation (RMSEA). Model 1 includes the variables: Court Number, USTA Level, Sky (player perception), Wind (player perception), Temperature (player perception), Water (on court), Shade (on court), Lines (visibility), Net (condition), Racquet (age), Strings (age), Grip (age), Tennis balls (age), Wind (actual), Cloud Cover (percentage), Preparation (of court), and Water Time (of the previous night); Model 2 includes: Sky (player perception), Wind (player perception), Temperature (player perception), Water (on court), Shade (on court), Lines (visibility), Net (condition), Racquet (age), Strings (age), Grip (age), Preparation (of court), and Water Time (of the previous night); and Model 3 includes: Sky (player perception), Wind (player perception), Temperature (player perception), Water (on court), Shade (on court), Lines (visibility), Net (condition), Racquet (age), Strings (age), Preparation (of court), and Water Time (of the previous night). ${ }^{* * *}$ denotes that all models tested are significant at the $\mathrm{p}<0.01$ level.

From Table 2, Model 3 (eliminating Court Number, USTA Level, and Grip (age) as well as combining Wind (actual) and Wind (player perception) and Sky (player perception) and Cloud Cover (percentage)) produces a considerably better fit than the other models. Model 3 produces a chi-square $\left(\chi^{2}\right)$ of $189.471(p<0.01)$ with 111 degrees of freedom. The other measures of fit include the comparative fit index (CFI) of .91, the standardized root mean square residual 
(SRMR) of .261, and the root mean square error of approximation (RMSEA) of .168, which suggests the variables are indistinguishable.

Table 3. Summary of Confirmatory Factor Analysis Results (Model 3)

\begin{tabular}{l|l}
\hline Item & Standardized Item Loadings \\
\hline Outside Court Factors & \\
\hline Average Variance Extracted (AVE) & .54 \\
\hline Composite Reliability & .17 \\
\hline 1. Today's sky was sunny. & .732 \\
\hline 2. There was no wind today. & .715 \\
\hline On-Court Factors & -.736 \\
\hline Average Variance Extracted (AVE) & \\
\hline Composite Reliability & .51 \\
\hline 1. There was no water on court. & .71 \\
\hline 2. There was no shade available for breaks. & .441 \\
\hline 3. The lines on court were not visible. & .773 \\
\hline 5. The net condition was extremely worn. & .840 \\
\hline Personal Equipment & .367 \\
\hline Average Variance Extracted (AVE) & .525 \\
\hline Composite Reliability & \\
\hline 1. I use a new racquet. & .34 \\
\hline 2. My strings are new. & .51 \\
\hline Court Preparation & .616 \\
\hline Average Variance Extracted (AVE) & .548 \\
\hline Composite Reliability & .16 \\
\hline 1. The court was prepared properly. & .27 \\
\hline The court was sufficiently watered. & .447 \\
\hline
\end{tabular}

This table reports the factor loadings, composite reliabilities, and the average variance extracted (AVE) for Model 3 (best fit). As noted previously, an Average Variance Extracted (AVE) above .50 is recommended, as is a Composite Reliability above .70 to meet acceptable measures of fit. Only the On-Court Factors meet the criteria.

Table 3 reports the factor loadings, composite reliabilities, and the average variance extracted (AVE) for Model 3 (best fit). Hair et al. (2010) suggest that standardized factor loading estimates should be .50 or higher. As illustrated in Table 3 , 7 of the 12 items used for the tennis variables are above the .50 threshold, while 2 are above .40 which indicates most of the items are loaded above or slightly below the recommended estimates. Additionally, Hair et al. (2010) recommend composite reliability estimates of .70 or higher to have confidence of fit.

The results in Table 3 provide mixed evidence of the quality of the measures used in this study. Of the four factors, only the On-Court Factors (Water, Shade, Lines, Net, and Clay) are acceptable $(>.70)$ in composite reliability with the average variance explained (AVE) above the recommended cutoff of .50 (Fornell \& Larcker, 1981). Outside Court Factors, Personal Equipment, and Court Preparation are clearly outside the acceptable standards of average variance extracted $(>.50)$ and composite reliability $(>.70)$. Given the unique nature of this study, it is not surprising that the scales produced inconsistent fit measures and will need further development.

\subsection{Means, Standard Deviations, and Variable Intercorrelations}

Table 4 displays the means, standard deviations and variable intercorrelations included in the study. Preliminary analysis reveals some interesting relationships. The highest correlation is the relationship between the perception of quality of the clay and the visibility of the lines $(r=.473)$, significant at the $\mathrm{p}<0.01$ level. This suggests that as the lines are move visible, the better players perceive the quality of clay. Another interesting relationship reveals that the more shade on court, the better the quality of clay $(\mathrm{r}=.338)$ is perceived, significant at the $\mathrm{p}<0.01$ level. 
Table 4. Means, Standard Deviations, and Variable Intercorrelations

\begin{tabular}{l|l|l|l|l|l|l|l|l|l|l|l|l|l}
\hline Variable & Mean & $\begin{array}{l}\text { Std. } \\
\text { Dev. }\end{array}$ & 1 & 2 & 3 & 4 & 5 & 6 & 7 & 8 & 9 & 10 & 11 \\
\hline 1.Sky & 1.73 & 1.14 & & & & & & & & & & & \\
\hline 2.Wind & 1.60 & .667 & .12 & & & & & & & & & & \\
\hline 3.Temperature & 3.93 & .847 & $-.56^{* *}$ & $-.256^{* *}$ & & & & & & & & & \\
\hline 4.Water & 5.83 & .923 & .082 & .145 & -.123 & & & & & & & & \\
\hline 5.Shade & 5.03 & 1.61 & $.390^{* *}$ & $.237^{* *}$ & $-.252^{* *}$ & $.338^{* *}$ & & & & & & & \\
\hline 6.Lines & 4.85 & 1.28 & .156 & .087 & -.118 & .053 & $.231^{*}$ & & & & & & \\
\hline 7.Net & 3.56 & 2.02 & .064 & .161 & -.062 & -.064 & .053 & $.221^{*}$ & & & & & \\
\hline 8.Clay & 5.63 & 1.32 & .094 & .052 & .031 & .126 & $.353^{* *}$ & $.473^{* *}$ & .065 & & & & \\
\hline 9.Racquet & 3.39 & 1.29 & -.029 & -.070 & .062 & $.192^{*}$ & .097 & $.183^{*}$ & -.146 & .168 & & & \\
\hline 10.Strings & 2.48 & 1.15 & .155 & -.097 & -.036 & .113 & -.075 & -.025 & .020 & .046 & $.314^{* *}$ & & \\
\hline 11.Prep & 3.28 & 2.47 & .132 & .049 & $-.215^{*}$ & .136 & .155 & .130 & .027 & .127 & -.090 & .147 & \\
\hline 12. Water Time & 7.88 & .927 & $-.596^{* *}$ & .155 & $.364^{* *}$ & .024 & -.201 & .049 & $.192^{*}$ & -.056 & .067 & -.049 & $-.308^{* *}$ \\
\hline This table & & & & & & & & \\
\hline
\end{tabular}

This table represents the means, standard deviations and variable intercorrelations of the variables used in this study. Sky: amount of sun experienced while playing, Wind: how windy the conditions felt, Temperature: how cool/hot the temperatures on court felt, Water: availability of drinking water on-court, Shade: availability of shade (for breaks between games), Lines: visibility of lines and how worn they appear to the participants, Net: appearance and apparent wear, Clay: plushness of the court, Racquet: age of racquet, Strings: newness of strings in racquet, Prep: the steps taken to get the courts ready for play in the morning prior to the participants beginning play, and Water Time: the amount (in minutes) of the above ground watering system placed on the courts during the previous night. ${ }^{* *}$ Correlation is significant at the 0.01 level (2-tailed). * Correlation is significant at the 0.05 level (2-tailed).

Not surprisingly, weather related variables, preparation, and watering time are correlated. Temperature reported by the players and sky (cloud coverage) are inversely related ( $r=-.56)$, significant at the $\mathrm{p}<0.01$ level. Cloud coverage generally affects temperature, and the player reported variables seem to indicate that the players on-court felt that as the cloud coverage increased, temperature felt cooler. Additionally, as the cloud coverage (sky) increased, the perceived shade on-court increased $(r=.390)$, significant at the $\mathrm{p}<0.01$ level. This generally falls in-line with expectations.

Personal equipment seems to have an impact on several factors. As reported, the newness of the player's racquet seems to influence the visibility of the lines ( $\mathrm{r}=.183)$, significant at the $\mathrm{p}<0.05$ level, while the newness of the strings is positively correlated to the newness of the racquet $(\mathrm{r}=.314)$, significant at the $\mathrm{p}<0.01$ level. This is a bit surprising, as generally a newer racquet (as opposed to brand new) does not necessarily equal new strings. Strings are replaced much more frequently than racquets, depending on the amount of playing frequencies.

\subsection{Evaluation of the Structural Model}

The study evaluates the relationships between the variables with controls in place for the effect of water time and court preparation. The models as reported in table 2, evaluate the variables with Model 3 being the best fit. Model 3 evaluates the Sky (player perception), Wind (player perception), Temperature (player perception), Water (on court), Shade (on court), Lines (visibility), Net (condition), Racquet (age), Strings (age) while controlling for Preparation (of court) and Water Time (of the previous night). Model $3\left(\chi^{2}=189.471\right.$, CFI $=.91$, SRMR=.261, RMSEA=.168) does exhibit a slightly better fit than Model $2\left(\chi^{2}=454.667, \mathrm{CFI}=.89, \mathrm{SRMR}=.291, \mathrm{RMSEA}=.172\right)$ and an improved fit over Model 1 $\left(\chi^{2}=719.591, \mathrm{CFI}=.38, \mathrm{SRMR}=.292, \mathrm{RMSEA}=.174\right)$.

Given the similarity in fit indices between Model 2 and Model 3, the application of the parsimony principle is warranted. While the chi-square of both Model 2 and Model 3 are different, the degrees of freedom, comparative fit index (CFI), standardized root mean square residual (SRMR), and root mean square error of approximation (RMSEA) are relatively similar. Generally, the model with fewer free parameters and more degrees of freedom is preferred (Muliak, 1998; Raykov \& Marcoulides, 1999). Thus, the selection of Model 3 is the most logical, as it is a simpler model and creates more stability in estimates and a higher likelihood that it will withstand rejection (Raykov \& Marcoulides, 1999). The observation of the intercorrelations combined with the parsimony principle concludes that Model 3 is preferred. 


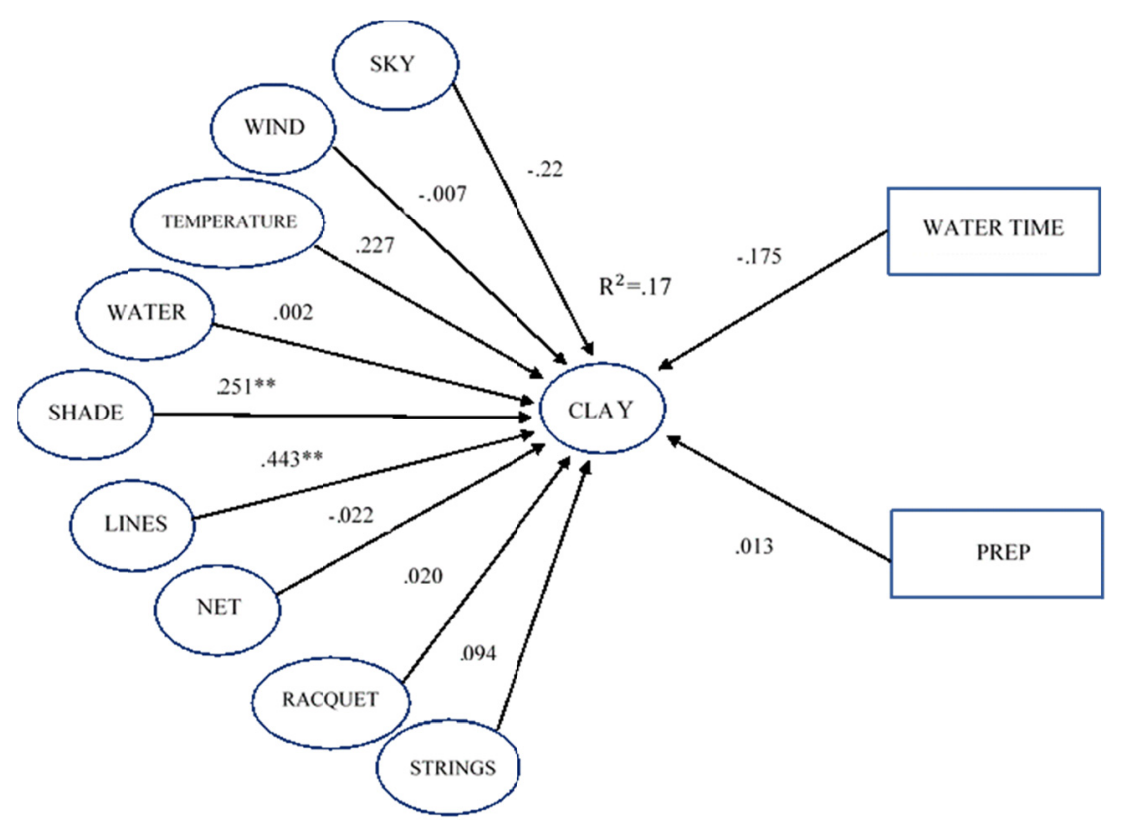

Figure 2. Final Model (Model 3) with Control Variables

Parameter estimates are shown; ${ }^{*} \mathrm{p}<0.05, * * \mathrm{p}<0.01$

The parameter estimates for Model 3 are shown in Figure 2. As illustrated, Sky, Wind, and Net all have negative relationships to the perception of the quality of clay. Temperature, Water, Racquet and Strings all have positive relationships to the perception of the quality of clay. Only 2 relationships are significant as Shade and Lines positively affect the perception of the quality of clay (both significant at $p<0.01$ ). Water Time and Preparation (control variables) are mixed with Water Time having a negative relationship to the perceived quality of clay and Preparation having a slightly positive relationship to the perceived quality of clay (both insignificant). Together, the variables explain $17 \%$ of the variance of the perceived quality of clay $\left(\mathrm{R}^{2}=.17\right)$.

\section{Robustness Tests}

This section reflects potential issues and addresses them in greater detail. From the structural equation modeling analysis, on-court factors appear to influence the perception of quality of the clay within acceptable levels. Only Water, Shade, Lines, and Net influence the perception of quality of the clay and are acceptable (>.70) in composite reliability with the average variance explained (AVE) above the recommended cutoff of .50 (Fornell \& Larcker, 1981). To determine if the study is encapsulating the effects associated with the perception of the quality of clay, the analysis includes a conditional regression analysis where the perception of the quality of clay is on the left-hand side of the regression and use Water, Shade, Lines, and Net as independent variables. The regression specification becomes:

$$
Y_{t}=\alpha_{i}+\beta_{1} \text { Water }+\beta_{2} \text { Shade }+\beta_{3} \text { Lines }+\beta_{4} \text { Net }
$$

where $\mathrm{Y}$ is the anticipated player perception of the quality of clay (dependent variable) at time $t 2$. Water, Shade, Lines and Net (all previously defined) are our variables of interest, and $\alpha_{i}$ is the constant (intercept).

Given the findings in the structural equation modeling, it is unsurprising that the Water and Net variables are insignificant. Strengthening the findings, Shade and Lines are significant when regressed against the perception of quality of the clay.

\footnotetext{
${ }^{2}$ We use time $t$ as a placeholder for the anticipated player perception of the quality of clay, as opposed to an additional measure impacting customer satisfaction in the regression analysis.
} 
Table 5. Regression Analysis for Water, Shade, Lines, and Net

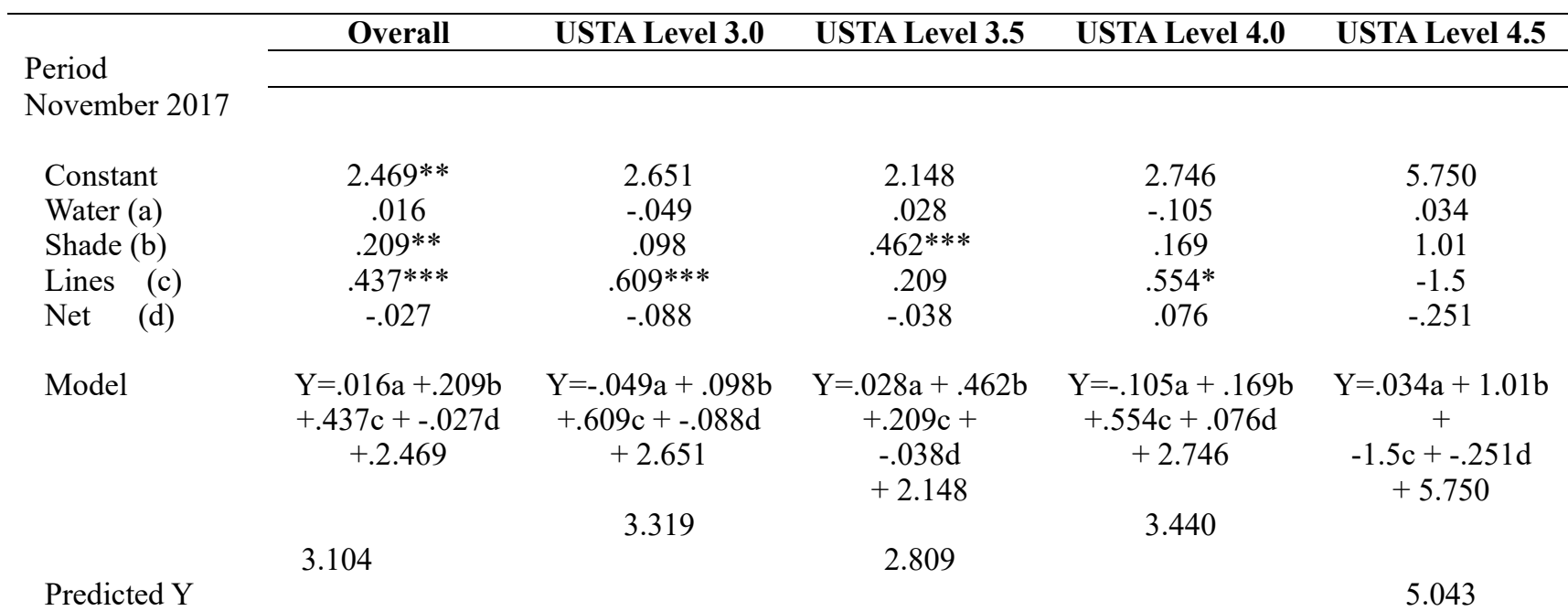

This table reports the conditional regression analysis for the perception of the quality of clay; survey collected during the month of November (2017). Building on the structural equation modeling results, we regress Water, Shade, Lines, and Net against the perception of Clay, while using the USTA Level as an additional control. The reported values for the Constant (Intercept), Predictors (gradient) of Water, Shade, Lines, and Net, USTA Level (control), Model (Regression Line), and the Predicted $\mathrm{Y}$ are shown. Significance levels are reported as: ${ }^{*}, * *, * * * .05, .01$ and .001 levels, respectively.

Additionally, other variables are examined to determine if any interactions to the perception of the quality of clay exist. The analysis finds no other significant relationships with the other variables and finds that Shade and Lines remain significant. ${ }^{3}$ Due to the unique nature of the perception of the quality of clay, the analysis includes the interaction of the level of play (participant skill level) as an additional control variable and its relationship to the perception of quality of clay. USTA Level (refer to the Appendix for skill level definitions) is the only additional control variable suitable to determine if skill level has an influence on the perception of the quality of clay. Thus, the regression specification becomes:

$$
Y_{t}=\alpha_{i}+\beta_{1} \text { Water }+\beta_{2} \text { Shade }+\beta_{3} \text { Lines }+\beta_{4} \text { Net }+\beta_{5} \text { USTA Level }
$$

where $\mathrm{Y}$ is the anticipated player perception of the quality of clay (dependent variable) at time $t$. Water, Shade, Lines and Net remain our variables of interest, while adding a control variable of USTA Level defined as the participant skill level (self-reported), and $\alpha_{i}$ is the constant (intercept).

Table 5 summarizes the values for the Constant (Intercept), Predictor (gradient) variables of Water, Shade, Lines, and Net, USTA Level (control variable), Model (Regression Line), and the Predicted value of Y for the regression between the perception of quality of clay and the variables.

The regressions between Clay and the variables are all positive. Given the previous analysis, the findings meet general expectations. However, by adding the control variable of USTA Level, Lines (visibility) become significant (only) to USTA Level 3.0 and USTA Level 4.0, while Shade (availability) becomes the only significant variable to USTA Level 3.5. There are no significant relationships for USTA Level 4.5. This suggests that skill level does make a difference in the perception of quality of clay.

\section{Conclusion}

The participant perception of the quality of clay courts contains unique information not considered in previous studies. Collecting a unique set of data from participants at a sports facility located in Brandon, Florida from November 1, 2017 through November 30, 2017, this study finds that participant perception of the quality of clay relies heavily on on-court amenities, more specifically the availability of shade (for breaks between games) and the visibility of lines (clarity). Using player perception (i.e. satisfaction), this study adds support to previous studies in confirming perceived quality and satisfaction. This study also lends further support to the expectancy disconfirmation theory and sheds light on a

\footnotetext{
${ }^{3}$ Interaction of all the remaining variables reveals that the constant, Shade and Lines remain significant, while the additional variables of Sky, Wind, Temperature, Restroom, Racquet, Strings, Grip, Tennis Balls, Temperature (Actual), Preparation (Court), and Water Time are insignificant.
} 
wrinkle in the theory that might be worth exploring: cost saving associated with meeting perceived quality. We also find there can be maintenance cost savings by focusing on what the consumer perceives as important.

There is mixed support for the hypotheses. Hypothesis 1 posits that outside court factors have no effect on participant perception of quality of clay, while the analysis finds that Sky and Wind have negative effects on the perception of quality of clay and Temperature has a positive effect on the perception of quality of clay (all insignificant). Hypothesis 2 posits that on-court amenities have a positive effect on participant perception of the quality of clay, while the analysis finds that Water, Shade, and Lines have a positive effect (Shade and Lines significant at $p<.01$ levels), Net has a negative effect on the perception of quality of the clay. Hypothesis 3 posits that personal equipment has a negative effect, while the analysis finds that both Racquet and Strings have a positive effect on the perception of the quality of clay (both insignificant). Hypothesis 4 posits that court preparation has a positive effect on the perception of quality of clay, but the analysis finds that Water Time has a negative effect and Court Preparation has a positive effect (both insignificant).

Given the unique findings, sports facilities can utilize this information by more closely aligning maintenance goals with participant perceptions (satisfaction) by using different measures to enhance member/player experience on clay courts, while reducing maintenance costs. While it is not prudent to advocate clay court neglect, there are cost saving methods to reduce labor on the courts (i.e. reduction of robust maintenance crews for court preparation) and keep members satisfied by focusing on providing shade for participants and diligently cleaning the lines on the court for many of the players. The findings do suggest that as the skill level increases, players are less inclined to perceive the quality of the clay courts by measures indicated in this study.

There are inherent limitations to this study. Of note is the development of the constructs. Due to the unique nature of this study (and lack of representation in the literature), improvement in both definition of the components and scales is warranted. The sample size is also limited, and a bigger sample size with a larger varying skill set of the participants would strengthen future studies. Different seasons throughout the year might have an impact on the perception of the quality of clay, as summers generally dry the clay out faster versus this study conducted later in the year. Clearly, these limitations will need attention in future studies.

\section{References}

Bolton, R. N., \& Lemon, K. N. (1999). A Dynamic Model of Customers' Usage of Services: Usage as an Antecedent and Consequence of Satisfaction. Journal of Marketing Research, 36(2), 171-186. https://doi.org/10.2307/3152091

Cronin, J. J. J., \& Taylor, S. A. (1992). Measuring Service Quality: A Re-examination and Extension. Journal of Marketing, 56(3), 55-68. https://doi.org/10.2307/1252296

Dabholkar, P. A., Shepherd, C. D., \& Thorpe, D. I. (2000). A Comprehensive Framework for Service Quality: An Investigation of Critical Conceptual and Measurement Issues Through a Longitudinal Study. Journal of Retailing, 76(2), 139-173. https://doi.org/10.1016/S0022-4359(00)00029-4

Erevelles, S., \& Leavitt, C. (1992). A Comparison of Current Models of Consumer Satisfaction/Dissatisfaction. Journal of Consumer Satisfaction, Dissatisfaction, and Complaining Behavior, 5(10), 104-114.

Fornell, C., \& Larcker, D. (1981). Evaluating Structural Equation Models with Unobservable Variables and Measurement Error. Journal of Marketing Research, 18(1), 39-50. https://doi.org/10.2307/3151312

Fredericks, J. O., \& Salter, J. M. II. (1998). What does your Customer Really Want? Quality Progress, 31(1), 63-65.

Haggar, M.S., Chatzisarantis, N., \& Biddle, S. (2002). A Meta-Analytic Review of the Theories of Reasoned Action and Planned Behavior in Physical Activity: Predictive Validity and the Contribution of Additional Variables. Journal of Sport and Exercise Psychology, 24, 3-32. https://doi.org/10.1123/jsep.24.1.3

Hair, J., Black, W., Babin, B., \& Anderson, R. (2010). Multivariate Data Analysis- 7th Edition. Prentice Hall Publishing.

Kang, J. (2002). A Structural Model of Image Based and Utilitarian Decision-Making Processes for Participant Sport Consumption. Journal of Sport Management, 16, 173-189. https://doi.org/10.1123/jsm.16.3.173

Kotler, P., \& Keller, K. L. (2006). Marketing Management (12 ${ }^{\text {th }}$ Edition). Upper Saddle River: Pearson Prentice Hall Inc.

Martin, L. (2015). Is Socioeconomic Status a Contributing Factor to Tennis Players' Success? Journal of Medicine and Science in Tennis, 20(3), 116-121.

McGehee, N. G., Yoon, Y., \& Cardenas, D. (2003). Involvement and Travel for Recreational Runners. Journal of Sport Management, 17(3), 305-324. https://doi.org/10.1123/jsm.17.3.305

Milne, G. R., \& McDonald, M. A. (1999). Sport Marketing: Managing the Exchange Process. Sudbury, MA: Jones and 
Bartlett.

Minocha, S., Dawson, L. H., Blandford, A., \& Millard, N. (2005). Providing Value to Customer in e-Commerce Environments: The Customer's Perspective. https://doi.org/10.4018/978-1-59140-824-6.ch006

Muliak, S. A. (1998). Parsimony and Model Evaluation. The Journal of Experimental Education, 66(3), $266-273$. https://doi.org/10.1080/00220979809604411

Noble, S. M., Haytko, D. L., \& Phillips, J. (2009). What Drives College-age Generation Y Consumers? Journal of Business Research, 62(2), 617-628. https://doi.org/10.1016/j.jbusres.2008.01.020

Oliver, R. I. (1997). Satisfaction: A Behavioral Perspective on the Consumer. New York, NY: McGraw-Hill, Inc.

Oliver, R. I., \& Desarbo, W. S. (1988). Response Determinants in Satisfaction Judgements. Journal of Consumer Research, 14(4), 495-507. https://doi.org/10.1086/209131

Oliver, R. I., \& Swan, J. E. (1989). Customer Perceptions of Interpersonal Equity and Satisfaction in Transactions: A Field Survey Approach. Journal of Marketing, 53(2), 21-35. https://doi.org/10.2307/1251411

Parasuraman, A., Zeithaml, V. A., \& Berry, L. L. (1985). A Conceptual Model of Service Quality and its Implications for Future Research. The Journal of Marketing, 49(4), 41-50. https://doi.org/10.2307/1251430

Raykov, T., \& Marcoulides, G. (1999). On Desirability of Parsimony in Structural Equation Model Selection. Structural Equation Modeling, 6(3), 292-300. https://doi.org/10.1080/10705519909540135

Singh, J. (1988). Consumer Complaint Intentions and Behavior: Definitional and Taxonomical Issues. Journal of Marketing, 52(1), 93-107. https://doi.org/10.2307/1251688

Sports Marketing Surveys (2005). [Global tennis participation rates]. Unpublished raw data.

Taylor, S. A. (1997). Assessing Regression-based Importance Weights for Quality Perceptions and Satisfaction Judgements in the Presense of Higher Order and/or Interaction Effects. Journal of Retailing, 73(1), 135-159. https://doi.org/10.1016/S0022-4359(97)90018-X

Tennis Industry Association (2004). 2004 U.S. Tennis Participation Study. Conducted: The Taylor Research and Consulting Group and Sport Marketing Surveys.

Tseng, S. C., \& Hung, S. W. (2013). A Framework Identifying the Gaps between Customers' Expectations and their Perceptions in Green Products. Journal of Cleaner Production, 59, 174-184. https://doi.org/10.1016/j.jclepro.2013.06.050

Tsiotsou, R. (2006). The Role of Perceived Product Quality and Overall Satisfaction on Purchase Intentions. Journal of Consumer Studies, 30(2), 207-217. https://doi.org/10.1111/j.1470-6431.2005.00477.x

Zeithaml, V. A., Berry, L. L., \& Parasuraman, A. (1996). The Behavioral Consequences of Service Quality. Journal of Marketing, 60(2), 31-46. https://doi.org/10.2307/1251929 


\section{Appendix}

Summary of USTA Levels (individual skill levels)

Level/Rating

3.0

3.5

4.0

4.5

Description

This player is consistent when hitting medium-paced shots, but they are not comfortable with all strokes. This player's shots lack directional control and power.

This player has achieved dependable stroke production with directional control on moderate-paced shots. They still lack depth and variety. This player is starting to show team work in doubles. This rating is considered an intermediate level.

This player has very dependable strokes including directional and depth control on both the forehand and backhand sides. This player can use ground strokes, volleys, lobs, overheads, and approach shots with success. This player occasionally forces errors. Rallies are often lost due to impatience. This player shows strong teamwork in doubles. High intermediate player. This is the bell curve in USTA league tennis.

In addition to directional and depth control, this player has begun to master the use of varying spin and power. This player can handle considerable pace and shows sound footwork. They can vary their game plan according to opponents. They can vary their serve and have placement on their second serve. This player tends to overhit on difficult shots. In addition to sound doubles teamwork, this player often shows aggressive net play. This is the beginning of the advanced ratings.

This table represents the USTA Levels of individual skills (taken from www.usta.com). The United States Tennis Association (USTA) uses these ratings to ensure similar skilled level players can compete against one another. The USTA uses the National Tennis Rating Program (NTRP) to assign a skill level. Ratings range from 1.0 (first time playing) to 7.0 (professional). Above are the ratings and a brief description of those skill levels (curtained to the participants of this study only).

\section{Copyrights}

Copyright for this article is retained by the author(s), with first publication rights granted to the journal.

This is an open-access article distributed under the terms and conditions of the Creative Commons Attribution license which permits unrestricted use, distribution, and reproduction in any medium, provided the original work is properly cited. 